\title{
Electronic Structure of MePc/Si(100) Surface Studied Using Metastable-Atom Induced Electron Spectroscopy*
}

\author{
Tomonori Ikari, ${ }^{\dagger}$ Kohei Matsuo, Shohei Uesugi, and Daichi Todo \\ National Institute of Technology, Ube Collage, Tokiwadai 2-14-1, Ube, 755-8555, Japan \\ Junko Ishii and Masamichi Naitoh \\ Graduate School of Life Science and Systems Engineering, \\ Kyushu Institute of Technology, Hibikino 2-4, Wakamatsu, Kitakyushu 808-0196, Japan
}

(Received 7 December 2015; Accepted 11 March 2016; Published 7 May 2016)

\begin{abstract}
Metal phthalocyanines $(\mathrm{MePc})$ have unique features applicable to the field of electronics and optics. In this study, we observe the surface electronic structure of $\mathrm{MePc}(\mathrm{Me}=\mathrm{Cu}, \mathrm{Zn})$ adsorbed $\mathrm{Si}(100)$ using metastable-atom induced electron spectroscopy (MIES). MePc molecules are deposited for less than $2000 \mathrm{~s}$ in vacuum at room temperature. At the initial adsorption of the $\mathrm{MePc}$, each molecule lays flat on the substrate and the center metal atom is on top. This orientation of the adsorbed molecules gradually changed with an increase in the deposition time of the MePc. When the MePc covered surface was annealed by direct current heating at $800^{\circ} \mathrm{C}$ or below, the molecules started to decompose and desorbed from the $\mathrm{Si}(100)$ surface. However, $\mathrm{Cu}$ atoms remained on the surface. We discuss the adsorption structure based on the deposition time and behavior of the MePc molecule with annealing.
\end{abstract}

[DOI: $10.1380 /$ ejssnt.2016.141]

Keywords: Metastable induced electron spectroscopy (MIES); Surface electronic phenomena (surface states); Silicon; Copper; Zinc

\section{INTRODUCTION}

Metal phthalocyanines $(\mathrm{MePc})$ have unique features for applications in the field of electronics and optics. For example, they can be employed in various devices such as solar batteries, sensors, and fuel cells. These features of $\mathrm{MePc}$ are attributed to the atomic bonding state and the molecular structure. The adsorption structures of $\mathrm{MePc}$ have already been observed on single crystal substrates using a scanning tunneling microscope (STM) [1, 2]. STM results were reported that the orientation of the adsorbed $\mathrm{MePc}$ depends on the structure of the substrate surface. The surface electronic structures of $\mathrm{CuPc}$ and $\mathrm{ZnPc}$ were calculated using theoretical methods such as density functional theory (DFT) [3-6]. These results showed partial density of states for each atom in the $\mathrm{CuPc}$ and $\mathrm{ZnPc}$ molecules.

In this study, we measure the surface electronic structure of $\mathrm{MePc}(\mathrm{Me}=\mathrm{Cu}, \mathrm{Zn})$ adsorbed $\mathrm{Si}(100)$ using metastable-atom induced electron spectroscopy (MIES). The MIES technique provides accurate measurements at the outermost surface. The detailed surface electronic structures obtained by MIES revealed the influence of the amount of adsorbed MePc molecules to their orientation on the surface. Moreover, we observed desorption and decomposition of MePc molecules at higher substrate annealing temperatures.

\footnotetext{
* This paper was presented at the 10th International Symposium on Atomic Level Characterizations for New Materials and Devices '15, Shimane Prefectural Convention Center (Kunibiki Messe), Matsue, Japan, 25-30 October, 2015.

$\dagger$ Corresponding author: t-ikari@ube-k.ac.jp
}

\section{EXPERIMENTAL}

The experimental setup comprised a helium metastabele atom $\left(\mathrm{He}^{*}\right)$ source, rear-view low energy electron diffraction (LEED) optics, retarding field energy analyzer, quadrupole mass spectrometer, and $\mathrm{MePc}$ evaporators. The base pressure was approximately $1.0 \times 10^{-7} \mathrm{~Pa}$. Helium atoms were excited to the metastable states by hotcathode low voltage discharge. The discharge was pulsed so that the fast photons and the slow $\mathrm{He}^{*}$ in the incident beam could be distinguished based on time of flight using a time-resolved detection technique. The raw data obtained by the retarding field energy analyzer, which integrated energy distributions, were differentiated numerically to yield MIES and UPS spectra. In MIES, the deexcitation of metastable atoms proceeds through different channels depending on the relation of the work function at the surface. At high work function surfaces such as clean $\mathrm{Si}(100)$ in Fig. 1(a), He* undergoes resonance ionization followed by Auger neutralization $(\mathrm{RI}+\mathrm{AN})$. The AN process takes place close to the topmost layers, and the MIES spectrum reflects a convolution of partial density of states at the surface.

The sample was a $\mathrm{Si}(100)$ substrate of P-doped n-type, cleaned in vacuum by direct-current Joule heating. A $\mathrm{Si}(100)$ clean surface was confirmed by a double-domain $(2 \times 1)$ LEED pattern. The sample temperatures were measured with an optical pyrometer $\left(200-1600^{\circ} \mathrm{C}\right) . \mathrm{Cu}$ or Zn phthalocyanine powder was inserted into the evaporator crucible. This crucible was heated by direct current to deposit MePc molecules at room temperature. We did not measure the amount of adsorbed MePc molecules; instead, we determined its index based on the deposition time. To determine the coverage or film thickness, observations using analytical techniques are necessary. During sample surface preparation, outgassing products of rel- 


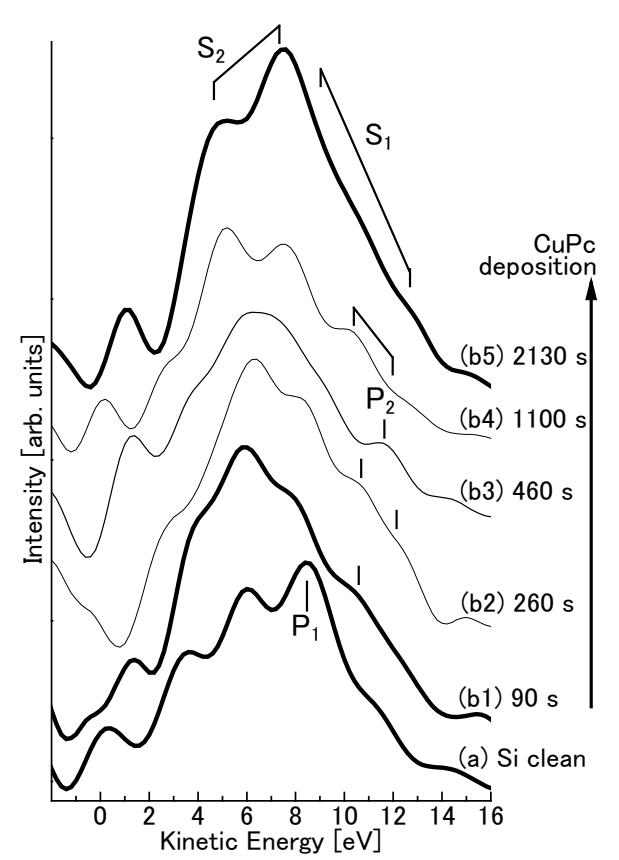

FIG. 1. Series of MIES spectra obtained for the $\mathrm{CuPc} / \mathrm{Si}(100)$ surface: (a) clean $\mathrm{Si}(100)$, (b1-b5) CuPc deposition time up to $2130 \mathrm{~s}$.

atively lightweight atoms and molecules were monitored using the quadrupole mass spectrometer.

\section{RESULTS AND DISCUSSIONS}

\section{A. CuPc/Si(100) surface}

We measured the MIES spectra for clean and $\mathrm{CuPc}$ deposited $\mathrm{Si}(100)$ surfaces up to the deposition time of $2130 \mathrm{~s}$ at room temperature. Figure 1 shows a series of MIES spectra for the $\mathrm{CuPc} / \mathrm{Si}(100)$ surface. In Fig. 1(a), at the $\mathrm{Si}(100)$ clean surface, the peak $\mathrm{P}_{1}$ at $8.4 \mathrm{eV}$ can be assigned to the Si-3p state. The peak at around 11.5 $\mathrm{eV}$ in Fig. 1(b3), labeled $\mathrm{P}_{2}$, is due to electron emission from the $\mathrm{Cu}$ induced states [7]. The theoretical calculations about the partial density of states of each atom composing the $\mathrm{CuPc}$ molecule were reported by some researchers $[3,4]$. We referred to these calculations for interpreting the origins of peak structures. The shoulder $\mathrm{S}_{1}$ at $9-12 \mathrm{eV}$ contained electron emissions for each atom $(\mathrm{Cu}, \mathrm{N}$, and $\mathrm{C})$ in the $\mathrm{CuPc}$ molecule. The intensity of peak $\mathrm{P}_{2}$ decreased with increasing $\mathrm{CuPc}$ deposition time. The peak structure $\mathrm{S}_{2}$ at $5-8 \mathrm{eV}$ originated from the electron emissions induced $\mathrm{C}$ atoms in $\mathrm{CuPc}$. In the MIES spectrum (b5), $\mathrm{S}_{2}$ made a significant contribution while the intensity of $\mathrm{P}_{2}$ decreased. This result implies that the $\mathrm{CuPc}$ adsorption structure changed from flat depending on the $\mathrm{CuPc}$ deposition time [8]. Namely, the adsorbed $\mathrm{CuPc}$ molecule lied flat on the substrate keeping the $\mathrm{Cu}$ atom on top at the initial stage of $\mathrm{CuPc}$ adsorption. However, at higher coverage, because $\mathrm{He}^{*}$ de-excited around $\mathrm{C}$ atoms at the outermost position in $\mathrm{CuPc}$, electron emission due to $\mathrm{C}$ induced states increased. It was possible that $\mathrm{CuPc}$ molecules were tilted upwards on the $\mathrm{Si}(100)$

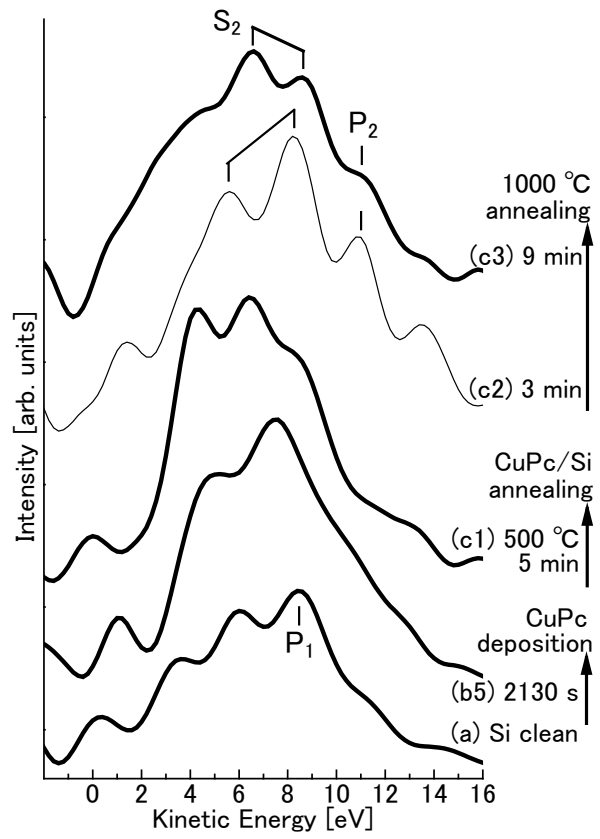

FIG. 2. Series of MIES spectra obtained for $\mathrm{CuPc} / \mathrm{Si}(100)$ surface with annealing: (a) clean $\mathrm{Si}(100)$, (b) CuPc_2130 $\mathrm{s} / \mathrm{Si}(100),(\mathrm{c} 1-\mathrm{c} 3)$ annealed at $1000^{\circ} \mathrm{C}$ and below.

surface.

Figure 2 shows a series of MIES spectra for the $\mathrm{CuPc}$ adsorbed $\mathrm{Si}(100)$ surface at different annealing temperatures. When the $\mathrm{CuPc} / \mathrm{Si}(100)$ surface was annealed at 400- $1000^{\circ} \mathrm{C}$, peaks $\mathrm{P}_{1}$ and $\mathrm{P}_{2}$ reappeared slightly with an increase in the annealing temperature. After annealing at $1000^{\circ} \mathrm{C}$ for $3 \mathrm{~min}$, the shape of several peaks were con-

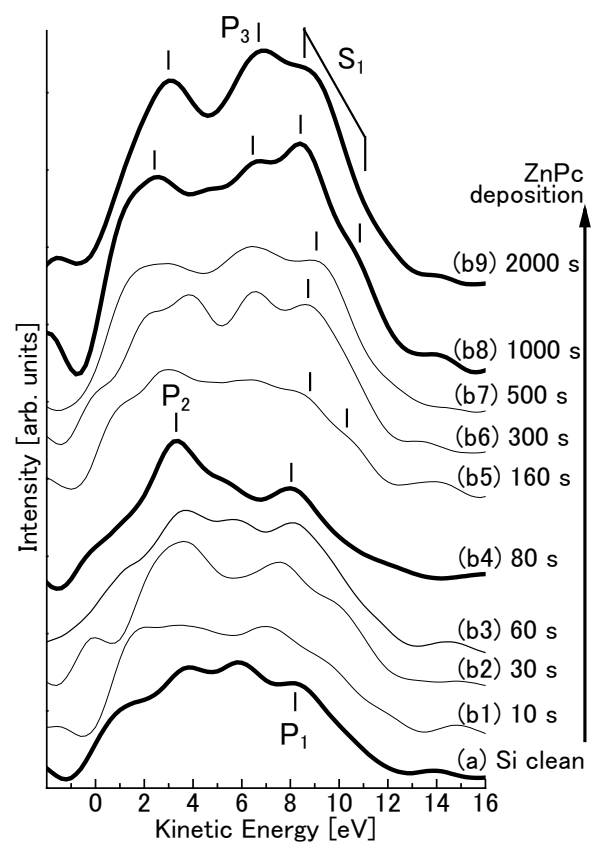

FIG. 3. Series of MIES spectra obtained for $\mathrm{ZnPc} / \mathrm{Si}(100)$ surface: (a) clean $\mathrm{Si}(100)$, (b1-b9) ZnPc deposition time up to $2000 \mathrm{~s}$. 


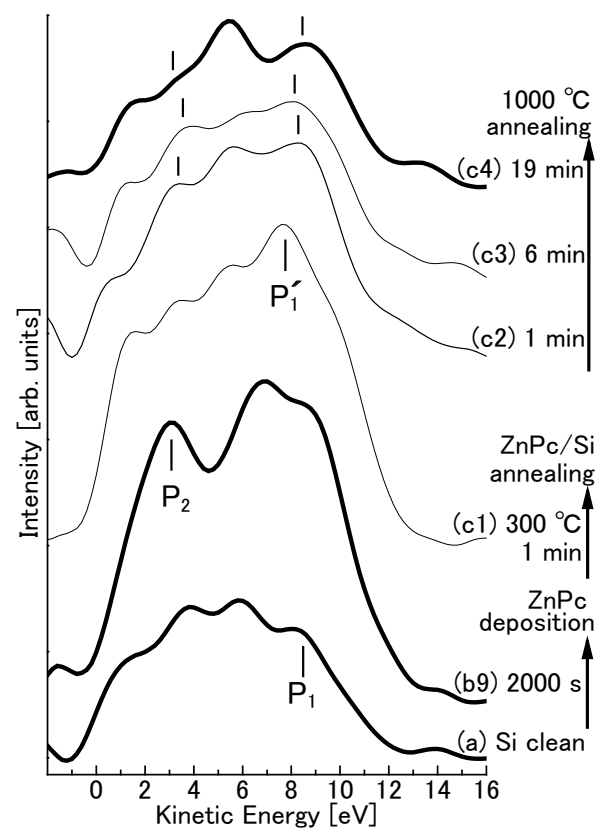

FIG. 4. Series of MIES spectra obtained for $\mathrm{ZnPc} / \mathrm{Si}(100)$ surface with annealing: (a) clean $\mathrm{Si}(100)$, (b) ZnPc_2000 $\mathrm{s} / \mathrm{Si}(100),(\mathrm{c} 1-\mathrm{c} 4)$ annealed at $1000^{\circ} \mathrm{C}$ and below.

firmed clearly in the spectrum (c2). As the pyrrole rings and aromatic rings in phthalocyanine were decomposed by annealing, the light elements $(\mathrm{N}, \mathrm{C}$, and $\mathrm{H}$ ) preferentially desorbed from the surface. Therefore, electron emissions were derived from residual $\mathrm{Cu}$ and $\mathrm{C}$ atoms or bare $\mathrm{Si}$ atoms. We found that $\mathrm{Cu}$ atoms remained on the $\mathrm{Si}(100)$ surface with annealing at $1000^{\circ} \mathrm{C}$ or less.

\section{B. ZnPc/Si(100) surface}

The MIES spectra obtained for the $\mathrm{ZnPc}$ deposited $\mathrm{Si}(100)$ surface are shown in Fig. 3. The interpretation for our MIES spectra was derived from the previously reported theoretical and experimental results of the surface electronic structures of the $\mathrm{ZnPc}$ molecule $[5,6,9]$. In Fig. 3(a), peak $\mathrm{P}_{1}$ was induced by a Si-3p state. The spectrum (a) for the Si clean surface exhibited peak positions for Si induced states were identical to its in Fig. 1(a). The shape of this spectrum in the low energy region reflects the influence of the secondary electrons. For a $\mathrm{ZnPc}$ deposition time of $80 \mathrm{~s}$, peak $\mathrm{P}_{2}$ caused by the electron emissions from the $\mathrm{Zn}$ atom appeared. As the spectrum (b4) reflects the density of states originating from the Si substrate, $\mathrm{ZnPc}$ molecules could not fully cover the surface but laid flat on keeping the $\mathrm{Zn}$ atom on-top. In Fig. 3(b5-b9), the shoulder structure $\mathrm{S}_{1}$ and the peak $\mathrm{P}_{3}$ at around $6.5 \mathrm{eV}$ appeared. $\mathrm{S}_{1}$ contains the electron emissions for each atom ( $\mathrm{N}$ and $\mathrm{C}$ ) in the $\mathrm{ZnPc}$ molecule. Peak $\mathrm{P}_{3}$ originated from the $\mathrm{C}$ atom. The intensity of $\mathrm{P}_{3}$ increased with $\mathrm{ZnPc}$ deposition time. These results suggested that the molecular plane of adsorbed $\mathrm{ZnPc}$ stood upright. The behavior of $\mathrm{ZnPc}$ on the $\mathrm{Si}(100)$ surface was similar to that of the $\mathrm{CuPc}$.

After $2000 \mathrm{~s} \mathrm{ZnPc}$ deposition, the $\mathrm{ZnPc} / \mathrm{Si}(100)$ sample (Fig. 3(b9)) was annealed at $300-1000^{\circ}$ C. Fig. 4 shows a series of MIES spectra for ZnPc adsorbed Si(100) surface with annealing temperatures. In Fig. 4(c1), the intensity of peaks $\mathrm{P}_{2}$ induced by $\mathrm{Zn}$ decreased slightly and a new peak $\mathrm{P}_{1}^{\prime}$ containing electron emission due to Si induced states was observed at around $7.8 \mathrm{eV}$ after annealing at $300^{\circ} \mathrm{C}$. This result suggests that $\mathrm{ZnPc}$ molecule started to decompose and the $\mathrm{Zn}$ atom desorbed from the surface at relatively low temperatures. When the $\mathrm{ZnPc} / \mathrm{Si}(100)$ surface was annealed at $1000^{\circ} \mathrm{C}$ for $19 \mathrm{~min}$, the position of peak $\mathrm{P}_{1}$ ' shifted to a higher energy. The intensity of $\mathrm{P}_{1}$ recovered, and $\mathrm{P}_{2}$ vanished in Fig. 4(c4). This MIES spectrum was roughly similar to that obtained for the Si clean surface indicating almost complete desorption of $\mathrm{ZnPc}$ and its decomposed species from the surface.

\section{CONCLUSIONS}

We measured the surface electronic structure of MePc $(\mathrm{Me}=\mathrm{Cu}, \mathrm{Zn})$ adsorbed $\mathrm{Si}(100)$ using MIES. The MePc absorption structures depend on deposition time. At the initial adsorption of $\mathrm{MePc}$, molecules laid flat on the substrate, keeping metal atoms on top of the surface. With increasing $\mathrm{MePc}$ deposition time, the orientation of $\mathrm{MePc}$ molecule became upright. It was found that even low temperature annealing triggered the decomposition of $\mathrm{CuPc}$ molecules. Then, the decomposed $\mathrm{Cu}$ atoms were directly bonded to the Si subsurface by high temperature annealing. Therefore, $\mathrm{Cu}$ atoms were not completely removed from the surface. In the case of the $\mathrm{ZnPc}$ adsorbed $\mathrm{Si}(100)$ surface, $\mathrm{ZnPc}$ started to desorb from the surface with low temperature annealing and finally desorbed approximately at $1000^{\circ} \mathrm{C}$ with the other decomposed elements.
[1] Y. Maeda, T. Matsumoto, M. Kasaya, and T. Kawai, Jpn. J. Appl. Phys. 35, L405 (1996).

[2] P. Amsalem, L. Giovanelli, J. M. Themlin, and T. Angot, Phys. Rev. B 79, 235426 (2009).

[3] B. Białek, I. G. Kim, and J. I. Lee, Thin Solid Films 436, 107 (2003).

[4] L. Lozzi, S. Santucci, S. La Rosa, B. Delley, and S. Picozzi, J. Chem. Phys. 121, 1883 (2004).

[5] Y. Y. Zhang, S. X. Du, and H.-J. Gao, Phys. Rev. B 84, 125446 (2011).
[6] B. Amin, S. Nazir, and U. Schwingenschlögl, Sci. Rep. 3, 1705 (2013).

[7] S. Krischok, P. Stracke, and V. Kempter, Appl. Phys. A 82, 167 (2006).

[8] S. Tokito, J. Sakata, and Y. Taga, Thin Solid Films 256, 182 (1995).

[9] L. Giovanelli, P. Vilmercati, C. Castellarin-Cudia, J.-M. Themlin, L. Porte, and A. Goldoni, J. Chem. Phys. 126, 044709 (2007). 